\title{
Article \\ AOT + Polyethylene Glycol Eutectics for Enhanced Oil Recovery
}

\author{
Cristina Gallego, Alba Somoza, Héctor Rodríguez (D) and Ana Soto * $\mathbb{C}$
}

Citation: Gallego, C.; Somoza, A.; Rodríguez, H.; Soto, A. AOT + Polyethylene Glycol Eutectics for Enhanced Oil Recovery. Appl. Sci. 2021, 11, 8164. https://doi.org/ 10.3390/app11178164

Academic Editor: Kun Sang Lee

Received: 3 August 2021

Accepted: 31 August 2021

Published: 2 September 2021

Publisher's Note: MDPI stays neutral with regard to jurisdictional claims in published maps and institutional affiliations.

Copyright: (c) 2021 by the authors. Licensee MDPI, Basel, Switzerland. This article is an open access article distributed under the terms and conditions of the Creative Commons Attribution (CC BY) license (https:// creativecommons.org/licenses/by/ $4.0 /)$.
CRETUS (Cross-Research in Environmental Technologies), Department of Chemical Engineering, Universidade de Santiago de Compostela, E-15782 Santiago de Compostela, Spain; cristina.gallego.rodriguez@rai.usc.es (C.G.); alba.somoza@rai.usc.es (A.S.); hector.rodriguez@usc.es (H.R.)

* Correspondence: ana.soto@usc.es

Abstract: Eutectic solvents are currently being proposed as useful chemicals for enhanced oil recovery (EOR). In this work, for the first time, the preparation of eutectics based on surfactants and polymers was proposed for this application. These chemicals can be tailored to offer the most desired properties for oil recovery: water/oil interfacial tension reduction and increase of the aqueous phase viscosity, while concomitantly facilitating their handling due to their liquid character at ambient conditions. Sodium bis(2-ethylhexyl)sulfosuccinate (AOT) and polyethylene glycol (PEG) of three different molecular weights (namely 600, 1000, and $2000 \mathrm{~g} / \mathrm{mol}$ ) were paired in a search for eutectic behaviors. Melting temperatures for all the systems were determined by differential scanning calorimetry. The most promising combination was AOT + PEG-600, which exhibited a melting point of $275 \mathrm{~K}$ and thermal stability up to $473 \mathrm{~K}$ at a $40: 60$ molar ratio. A promising value of $5.1 \times 10^{-2} \mathrm{mN} / \mathrm{m}$ was obtained for the interfacial tension between the optimized formulation and crude oil. The formulation was tested in core-holder experiments to extract oil from a sandstone rock at room temperature, achieving an encouraging $34 \%$ of additional oil recovery after the secondary extraction.

Keywords: eutectic; AOT; PEG; EOR

\section{Introduction}

In recent decades, global energy consumption has increased exponentially due to the rise in population, economic growth, and technological development. According to the U.S. Energy Information Administration, it is estimated that global primary energy consumption will increase approximately 40\% between 2019 and 2050 [1]. In this context, petroleum will be needed for many years both as an energy source and as a raw material for many essential products. The rate of discovery of new oil reservoirs is currently declining; therefore, long-term efforts should focus on increasing recovery from already exploited fields [2,3].

Nowadays, around 90\% of the world's oil is extracted by means of water flooding (secondary recovery). However, large amounts of water are required to maintain the pressure gradient inside the reservoir [4]. Additionally, water is far less viscous than crude oil and this can lead to a phenomenon known as viscous fingering. During the water injection process, the displacement front is unstable, with water flowing faster than crude oil and, thus, reaching production wells, while the crude remains in the earth $[5,6]$. Furthermore, capillary forces retain crude oil in the rock pores. For these reasons, about two-thirds of the original oil in place (OOIP) remains inside the reservoir after secondary flooding [7,8]. Enhanced oil recovery (EOR) processes include a wide range of methods that intend to increase the productivity and operative life of oilfields after conventional water flooding. EOR techniques comprise thermal recovery, miscible gas injection, and chemical methods. Among these options, chemical EOR is widely used for low- and medium-viscosity crudes, regardless of the type of rock formation [8]. 
Polymer flooding is a chemical EOR technique that can improve the sweep efficiency of water by reducing its mobility. Polymers are inexpensive chemicals that can be added to the displacing phase to increase its viscosity and thus reduce the viscous fingering effects [2]. Other chemical agents that are widely used in EOR are surfactants. The main functions of surfactants are the reduction of the water/oil interfacial tension (IFT) and the alteration of the wettability [8]. IFT reduction is the most important mechanism to increase the capillary number and thus enhance oil mobility, allowing it to be flushed out of the reservoir. Ultra-low water/oil IFT values are required to obtain high oil recovery. Besides decreasing the IFT, surfactants can also alter the wettability of the rock towards water-wet by adsorbing on the reservoir surface $[9,10]$.

Combined chemical EOR methods are being implemented in most cases, since they can exploit the synergy of different substances during the extraction process [11]. In particular, surfactant-polymer (SP) flooding is employed to mitigate the degradation of the surfactant, decrease the aqueous mobility of the formulation, and improve the economics of the process [12]. Therefore, including polymer in a surfactant slug is practically a requirement for maintaining a favorable mobility ratio [13]. The current application of the method involves the manipulation of polymers and surfactants that are often solid at ambient conditions, thus representing an additional difficulty in the preparation of the formulations to be injected. As an advance in the application of the method, the use of eutectics combining these chemicals is proposed for the first time in this work.

The term "eutectic" is applied to describe an isothermal reversible reaction of a liquid phase that is turned into two or three different solid phases during cooling [14]. In other words, a eutectic is a binary or ternary mixture with a melting point lower than those of the pure components. Recently, (deep) eutectic solvents have received great attention for EOR applications. However, the literature to date on this specific niche of research is very limited and it does not focus on the combination of polymers and surfactants. Rather, it focuses on the reduction of the melting point of the eutectic, independently of the character of the compounds that are being mixed. Mohsenzadeh et al. [15] were the first authors to propose the use of these chemicals for EOR. Eutectics composed of choline chloride $(\mathrm{ChCl})$ and either glycerol or urea were tested for the application, achieving a respectable level of EOR mainly due to viscosity increase and wettability alteration. However, the high concentration of the eutectic mixture used in the aqueous formulation $(50 \mathrm{vol} \%$ ) would likely render the method economically unfeasible in a practical scale. Mixtures of $\mathrm{ChCl}$ and ethylene glycol were proposed by Shuwa et al. [16], obtaining tertiary oil recoveries in the range of $6 \%$ to $16 \%$ of OOIP, but again using a concentration much greater (by a factor of ca. 50 ) than the usual chemical concentrations in EOR. Laboratory-scale screening, based on microemulsion generation, of different chemicals was carried out by Lee and Badagli [17]. The 2-hydroxyethyltrimethylammonium chloride + urea, 2-hydroxyethyltrimethylammonium chloride + propanetriol, and sodium carbonate + propanetriol eutectics were found to be unable to form oil-in-water emulsions and discarded for further studies. Al-Wahaibi et al. combined $\mathrm{ChCl}$ and malonic acid at two different concentrations, producing $7-14 \%$ of the residual heavy oil after brine flooding, and with wettability alteration identified as the dominant mechanism for the oil recovery. They found better performance at higher temperatures [3]. El-hoshoudy et al. [18] proposed the use of quaternary ammoniumbased eutectics for the application. They used molecular dynamic simulation to study interactions between oil and eutectics, and the efficacy of the method was tested experimentally at low scale and by simulation at field scale. Core-flooding tests were carried out by Sanati et al. [19] with aqueous formulations ( $1 \mathrm{vol} \%)$ of the ionic liquid 1-dodecyl-3methylimidazolium chloride and the eutectic formed by choline chloride and citric acid. As in previous cases, the eutectic was not able to reduce the IFT, which is the reason why the authors proposed its combination with a very low concentration of cetyltrimethylammonium bromide $(\mathrm{CTAB})$ as co-surfactant. The ionic liquid performed slightly better than the eutectic-CTAB mixture for EOR. Recently, these authors proposed the use of ionic liquids and eutectic solvents as potential inhibitors to reduce CTAB adsorption [20]. 
The combination of the chemicals generally used in EOR with the advantages of eutectics may constitute a promising approach, as this would greatly facilitate the preparation of the formulations. Thus, in this work, the use of a eutectic mixture composed of a surfactant and a polymer was proposed for EOR. The traditional anionic surfactant sodium bis(2-ethylhexyl)sulfosuccinate, also known as sodium docusate or as AOT, was selected for its capacity to reduce IFT. Polyethylene glycol (PEG) was selected as polymer due to its capacity to form hydrogen bonds, thermal and chemical stability, viscosifying power, low adsorption on rock surfaces, low toxicity, and low cost. Solid-liquid equilibria were studied for the different surfactant/polymer systems, looking for a eutectic behavior. An optimal formulation was defined through the minimization of water/oil IFT by changing salinity. Finally, adsorption tests and a core flooding experiment in sandstone were carried out to analyze the capability of the formulation to extract oil.

\section{Materials and Methods}

\subsection{Materials}

AOT, with purity $>97 \mathrm{wt} \%$, was purchased from Sigma-Aldrich (St. Louis, MO, United States). PEG of molecular weights $600 \mathrm{~g} / \mathrm{mol}$ (Merck KGaA, $>99 \mathrm{wt} \%$ ), $1000 \mathrm{~g} / \mathrm{mol}$ (Sigma Aldrich, $>99 \mathrm{wt} \%$ ), and $2000 \mathrm{~g} / \mathrm{mol}$ (Sigma Aldrich, $>99 \mathrm{wt} \%$ ) were used as polymers. Prior to characterization and use, surfactant and polymers were purified under high vacuum (absolute pressure lower than $1 \mathrm{~Pa}$ ) while heated at moderate temperature (343-373 K) to eliminate water and other volatile impurities. Residual water content was determined by Karl-Fischer titration in a Metrohm 899 coulometer. Solid materials were solubilized in ethanol and their water content was corrected according to the water content of the solvent. The chemical identity of all compounds was confirmed by ${ }^{1} \mathrm{H}$ NMR spectroscopy in a Varian Mercury 300 spectrometer, using dimethylsulfoxide-d6 (Sigma Aldrich, purity $>99 \mathrm{wt} \%$, deuteration degree $99.5 \%$ ) as deuterated solvent. The obtained NMR spectra were processed with the MestRe-C software and are shown in the Supplementary Materials.

Brine solutions were prepared by dissolving different amounts of sodium chloride $(\mathrm{NaCl})$ in distilled water. Crude oil, with the properties listed in Table 1, was kindly supplied by Repsol (refinery of A Coruña, Spain).

Table 1. Properties of crude oil (provided by supplier).

\begin{tabular}{|c|c|}
\hline Property & Value \\
\hline Density at $288.15 \mathrm{~K}\left(\mathrm{~kg} / \mathrm{m}^{3}\right)$ & 811.1 \\
\hline Reid vapor pressure (kPa) & 44.9 \\
\hline Viscosity at $293.15 \mathrm{~K}$ (cSt) & 4.861 \\
\hline Carbon residue $(w \mathrm{t} \%)$ & 1.2522 \\
\hline Asphaltenes (wt $\%)$ & 0.4624 \\
\hline $\mathrm{API}^{\circ}$ & 42.9 \\
\hline
\end{tabular}

Sandstone cores used in adsorption and core flooding tests were composed of $86.47 \mathrm{wt} \%$ of silica and $7.31 \mathrm{wt} \%$ of alumina, with traces of inorganic oxides. Cores were supplied by Vinci Technologies.

\subsection{Methods}

\subsubsection{Determination of Eutectics}

Mixtures of AOT with PEG polymers of different molecular weight were prepared in order to search for a eutectic behavior via the plot of melting temperatures against composition [21]. Samples with a molar composition step of ca. 0.10 were prepared for each system, covering the entire composition range. All the samples were prepared by weight in a Mettler Toledo XPE205 analytical balance with an uncertainty of $2 \times 10^{-4} \mathrm{~g}$.

Differential scanning calorimetry (DSC) experiments were run in a TA Instruments Q2000 differential scanning calorimeter, with an RCS 90 cooling system attached. Approximately $5-15 \mathrm{mg}$ of sample were placed in a $40-\mu \mathrm{L}$ hermetic aluminum capsule and 
loaded onto the measuring chamber with an autosampler. An analogous empty capsule was employed as a reference, and a $50-\mathrm{mL} / \mathrm{min}$ nitrogen flow was used as sample purge gas. The thermal program consisted of three cycles, each of them composed by one heating ramp and one cooling ramp with rates of $5 \mathrm{~K} / \mathrm{min}$, and 10-min isotherms in between ramps. It was ensured that the curves corresponding to the second and third cycle were essentially coincident, and the thermogram of the third cycle was used to determine thermal events. Melting temperatures were determined as onset of the endothermic peaks. DSC thermograms were analyzed using the software Universal Analysis 2000, version 4.5.0.5, by TA Instruments. All the experiments were performed at least twice to ensure repeatability.

\subsubsection{Thermal Stability}

The thermal stability of pure compounds and eutectic mixture was measured by thermogravimetric analysis (TGA) in dynamic mode [21] using a TA Instruments Q500 thermogravimetric analyzer. Samples (ca. 5-20 mg) were placed in an open platinum pan, loaded into the measuring chamber, and heated at a rate of $5 \mathrm{~K} / \mathrm{min}$ from room temperature to $773 \mathrm{~K}$. Nitrogen (Praxair, $99.999 \%$ ) was used as a balance purge gas (flow rate of $40 \mathrm{~mL} / \mathrm{min}$ ) and as a sample purge gas (flow rate of $60 \mathrm{~mL} / \mathrm{min}$ ). The weight precision of the instrument was $0.01 \%$. Regular onset decomposition temperature $T_{d}$ and $5 \%$ onset decomposition temperature $T_{d, 5 \%}$ (onset using a tangent to the TGA curve at a sample mass loss of $5 \%$ ) were determined. Thermograms were analyzed using the software Universal Analysis 2000, version 4.5.0.5, by TA Instruments. All the experiments were performed at least twice to ensure repeatability.

\subsubsection{Physical Characterization of the Eutectic}

The determination of density at different temperatures was conducted at atmospheric pressure in an Anton Paar vibrating U-tube DMA 5000 density meter with automatic viscosity correction and self-control of the temperature to $0.01 \mathrm{~K}$ based on the Peltier effect. The uncertainty in density measurement was $3 \times 10^{-5} \mathrm{~g} / \mathrm{cm}^{3}$ (standard uncertainty calculated as the standard deviation of the mean of three independent observations). An Anton Paar Lovis 2000 ME rolling-ball viscosimeter was used to determine the dynamic viscosity with an uncertainty of $0.5 \%$. Prior to viscosity measurement, a rheological analysis was performed to confirm the Newtonian behavior of the samples. All the experiments were performed at least twice to ensure repeatability.

\subsubsection{EOR}

Injectability

Solubility of the selected eutectic mixture in different brines was tested. To that aim, a stock solution of eutectic and different brines was prepared in distilled water by weight. Aqueous formulations with $1 \mathrm{wt} \%$ of surfactant and the desired $\mathrm{NaCl}$ concentration (from 1 to $5 \mathrm{wt} \% \mathrm{NaCl}$ ) were prepared by adding different brines to the stock solution of eutectic. Finally, formulations were vigorously shaken and left to equilibrate for $24 \mathrm{~h}$. Those formulations showing cloudiness or precipitation were discarded.

\section{Water/Oil IFT Reduction}

A Krüss SITE100 spinning drop tensiometer was employed to measure dynamic IFT between crude oil and stable eutectic formulations [22]. The temperature was kept constant at $298.15 \mathrm{~K}$ using circulating oil from a Julabo EH-5 thermostatic bath. The capillary tube was filled with the aqueous solution as bulk phase ensuring the absence of air bubbles. A drop of $4 \mu \mathrm{L}$ of crude oil was then injected into the middle of the capillary tube using a Hamilton micro-liter syringe, while rotating at low speed (500 rpm). Immediately after that, the rotating velocity was raised to $5000-9000 \mathrm{rpm}$, in order to obtain a drop with a length at least four times longer than its diameter. IFT $(\mathrm{mN} / \mathrm{m})$ was calculated according to the Vonnegut equation [23]:

$$
I F T=\frac{\Delta \rho \cdot \omega^{2} \cdot D^{3}}{32}
$$


where $\Delta \rho\left(\mathrm{g} / \mathrm{cm}^{3}\right)$ is the density difference between dense and light phase, $\omega$ is the angular velocity $\left(\mathrm{s}^{-1}\right)$, and $D$ is the diameter of the oil drop $(\mathrm{cm})$. All the experiments were performed at least twice to ensure repeatability.

\section{Adsorption Kinetics}

Sandstone core was crushed to small pieces and then sieved to achieve a uniform particle size in the range of $0.5-1.0 \mathrm{~mm}$. Approximately $1 \mathrm{~g}$ of this rock was placed in several glass vials together with $9 \mathrm{~g}$ of the optimized formulation (water with $1 \mathrm{wt} \%$ eutectic and $0.5 \mathrm{wt} \% \mathrm{NaCl}$ ). The vials were then shaken under controlled conditions (atmospheric pressure and $298.15 \mathrm{~K}$ ) in a Selecta Boxcult orbital shaker. To determine the kinetic behavior of the adsorption process, a sample was taken from each vial at different times. All samples were centrifuged at $1000 \mathrm{rpm}$ during $30 \mathrm{~min}$ in an Ortoalresa Digicen $21 \mathrm{R}$ centrifuge. The supernatant was filtered and analyzed using an Agilent UV-Vis 8453 spectrophotometer. The apparatus was previously calibrated at a wavelength of $215 \mathrm{~nm}$. The surfactant adsorption was calculated as follows [24]:

$$
q_{t}=\left(C_{0}-C_{e}\right) \cdot \frac{V_{s}}{m}
$$

where $q_{t}$ is the surfactant adsorption density (mg/g rock) at a certain time $t$ (it becomes $q_{e}$ when the system reaches the equilibrium), $C_{0}$ is the initial concentration of surfactant in the solution $(\mathrm{mg} / \mathrm{L}), C_{e}$ is the concentration of surfactant in the solution after reaching equilibrium $(\mathrm{mg} / \mathrm{L}), V_{s}$ is the volume of solution added originally $(\mathrm{L})$, and $m$ is the mass of crushed rock (g).

Two commonly used kinetic models were evaluated to describe the adsorption behavior. The pseudo-first-order kinetic model, developed by Lagergren in 1898 [25], is mathematically expressed as:

$$
\log \left(q_{e}-q_{t}\right)=\log \left(q_{e}\right)-\frac{K_{1}}{2.303} t
$$

where $q_{e}$ represents the equilibrium adsorption density $\left(\mathrm{mg} / \mathrm{g}\right.$ rock) and $K_{1}$ is the rate constant $\left(\mathrm{h}^{-1}\right)$. As an alternative, the linearized pseudo-second-order kinetic equation was also tested:

$$
\frac{t}{q_{t}}=\frac{1}{q_{e} K_{2}}+\frac{t}{q_{e}}
$$

where $K_{2}$ introduces the rate constant of the pseudo-second-order model $\left(\mathrm{h}^{-1}\right)$.

\section{Static Adsorption Experiments}

In order to investigate the effect of the polymer on the surfactant adsorption, static experiments were carried out for both the eutectic mixture and the surfactant alone. To that end, $1 \mathrm{~g}$ of crushed sandstone was added to $9 \mathrm{~g}$ of solution with concentrations of the eutectic ranging from $500 \mathrm{ppm}$ to $10,000 \mathrm{ppm}$, or to the same mass of solution with surfactant concentrations ranging from $165.5 \mathrm{ppm}$ to $3310 \mathrm{ppm}$ (equalizing the concentrations of surfactant in the eutectic solutions). The salinity of all solutions was fixed at $0.5 \mathrm{wt} \%$ $\mathrm{NaCl}$. All the samples were agitated for $24 \mathrm{~h}$ at $298.15 \mathrm{~K}$ and left for another $24 \mathrm{~h}$ to reach equilibrium. After this time, solutions were centrifuged at $1000 \mathrm{rpm}$ for $30 \mathrm{~min}$ and then filtered. The final concentration of AOT was determined by UV-Vis spectrophotometry.

Two of the most common models used to fit the adsorption isotherms of surfactants are the Langmuir and Freundlich isotherms, which describe the phenomena of adsorption with non-linear curves [24]. According to the Langmuir model, the adsorption occurs in a monolayer fashion and there is no interaction between molecules [26]. The isotherm is given by the following equation:

$$
q_{e}=q_{m} K_{L} \cdot \frac{C_{e}}{1+K_{L} C_{e}}
$$


in which $q_{m}$ is the maximum amount of adsorbed surfactant $(\mathrm{mg} / \mathrm{g}), K_{L}$ is the Langmuir equilibrium constant $(\mathrm{L} / \mathrm{mg})$, and $C_{e}$ is the concentration of surfactant at equilibrium $(\mathrm{mg} / \mathrm{L})$.

On the other hand, the Freundlich model describes multilayer adsorption [26] with the following equation:

$$
q_{e}=K_{F} C_{e}^{\frac{1}{n}}
$$

where $K_{F}$ is the constant of Freundlich adsorption $(\mathrm{L} / \mathrm{g})$ and $n$ is an empirical constant related to adsorption intensity: If $0.1<1 / n<0.5$, adsorption will be favorable; if $0.5<1 / n \leq 1$, adsorption will be easily attainable; if $1 / n>1$, adsorption will be almost impossible [25].

\section{Oil Recovery}

Core-flooding experiments are definitive tests in order to check the efficacy of a formulation for EOR $[12,13,22,27,28]$. The core-flooding system used in this work consisted of a Hassler H00 0210 core holder and two floXlab BTSP 500-5 piston pumps (equipped with an accurate pressure sensor), one for aqueous solutions and another for crude oil. Core holder and pumps were purchased from Vinci Technologies. Given the anionic character of the surfactant, a sandstone core of $3.84 \mathrm{~cm}$ diameter and $7.62 \mathrm{~cm}$ length was used for the test. A confining pressure of 50 bar was established using an Enerpac P142 manual hydraulic pump, and it was maintained at a value at least 35 bar higher than the flooding pressure in order to prevent hydraulic side flow. Experiments were performed at room temperature.

The core was subjected to a vacuum for $24 \mathrm{~h}$, and then it was flooded with brine $(0.5 \mathrm{wt} \% \mathrm{NaCl})$. After $24 \mathrm{~h}$, the rock was characterized by determining the pore volume $(\mathrm{PV})$, using its dry and wet weights. To determine the absolute permeability $\left(k_{w}\right)$ of the rock, the injection flow rate was varied between $1 \mathrm{~mL} / \mathrm{min}$ and $10 \mathrm{~mL} / \mathrm{min}$, recording for each value the pressure difference between the inlet and outlet points $(\triangle P, \mathrm{~Pa})$. The plot of the injection flow rate versus the pressure drop yields a straight line with a slope that enables the calculation of the absolute permeability of the brine using Darcy's law [29]:

$$
q=\frac{\Delta P}{\eta} \cdot \frac{A}{L} \cdot k_{w}
$$

where $q$ is the injection rate $\left(\mathrm{m}^{3} / \mathrm{s}\right), \eta$ is the dynamic viscosity of the brine (Pa.s), $A$ is the cross-sectional area $\left(\mathrm{m}^{2}\right)$, and $L$ is the length of the core $(\mathrm{m})$.

After this characterization, the core was flooded with crude oil at an increasing injection rate, from $2 \mathrm{~mL} / \mathrm{min}$ to $10 \mathrm{~mL} / \mathrm{min}$, until the effluent was free of water (oil cut $>99 \%$ ). OOIP was determined as the difference between crude oil injected and crude oil recovered. Equations (8) and (9) were used to calculate the initial oil saturation $\left(S_{o i}\right)$ and initial water saturation $\left(S_{w i}\right)[22,27,28]$ :

$$
\begin{gathered}
S_{o i}(\%)=\frac{O O I P \cdot 100}{P V} \\
S_{w i}(\%)=\frac{(P V-O O I P) \cdot 100}{P V}
\end{gathered}
$$

Subsequently, the core was allowed to rest for 6 days. After this aging period, $4-5 \mathrm{PV}$ of brine $(0.5 \% \mathrm{NaCl})$ were injected at a constant flow rate of $2 \mathrm{~mL} / \mathrm{min}$. This step, corresponding to the secondary recovery, lasted until the differential pressure remained constant and oil was no longer obtained at the outlet stream (oil cut $<1 \%$ ). Oil Recovered After Water Flooding (ORWF) was measured in graduated glass cylinders, and residual oil saturation $\left(S_{o r}\right)$ was determined as the percentage of oil remaining in the core. Finally, the tertiary recovery step was carried out. To that aim, the core was flooded with $4-5 \mathrm{PV}$ of $1 \mathrm{wt} \%$ eutectic mixture in $0.5 \mathrm{wt} \% \mathrm{NaCl}$ at a constant flow rate of $2 \mathrm{~mL} / \mathrm{min}$. Oil 
recovered after tertiary flooding was measured, and the Additional Oil Recovery (AOR) was calculated as a percentage of the OOIP.

\section{Results and Discussion}

\subsection{Determination of Eutectics}

Table 2 shows water content and melting temperatures for the pure compounds used in this work. DSC thermograms can be found in the Supplementary Materials. Some differences are found with previously published data. It should be noted that not all the results coming from previous works indicate the water content of the samples and, in most cases, chemicals were not dried prior to the experiments. Moisture content has a substantial impact on thermal and mechanical properties of polymers [30] and organic salts [31], thus providing a reason for the differences observed.

Table 2. Water content and thermal characterization of pure compounds.

\begin{tabular}{|c|c|c|c|c|c|}
\hline & & $T_{d}(\mathrm{~K})$ & $T_{d, 5 \%}(\mathrm{~K})$ & $T_{m \text { (onset) }}(\mathrm{K})$ & $\begin{array}{l}\text { Water Content } \\
\text { (ppm) }\end{array}$ \\
\hline \multirow{2}{*}{ AOT } & Exp. & 510 & 485 & 404 & 596 \\
\hline & Lit. & 533 [32] & - & 428 [33] & - \\
\hline \multirow[b]{2}{*}{ PEG-600 } & Exp. & 597 & 518 & 285 & 393 \\
\hline & Lit. & $623-650[34]^{*}$ & - & $283[35]$ & - \\
\hline \multirow{2}{*}{ PEG-1000 } & Exp. & 645 & 575 & 304 & 250 \\
\hline & Lit. & $650-675[36,37]$ * & - & 304 [38] & - \\
\hline \multirow{2}{*}{ PEG-2000 } & Exp. & 638 & 574 & 319 & 174 \\
\hline & Lit. & $650-675[36,39]$ * & - & $323[38]$ & - \\
\hline
\end{tabular}

* Ranges estimated graphically from plots of the TGA curves.

AOT is solid at ambient conditions, and melting points of the polymers range from $285 \mathrm{~K}$ (PEG-600) to $319 \mathrm{~K}$ (PEG-2000). The existence of a eutectic for these mixtures could allow for easy manipulation of the surfactant while two chemicals of interest for EOR are combined. For that reason, solid-liquid equilibria of the systems AOT + PEG-2000, AOT + PEG-1000, and AOT + PEG-600 were determined using DSC. Figure 1 shows the melting temperatures of the mixtures as a function of AOT mole fraction (numerical data are shown in Table S1 in the Supplementary Materials).

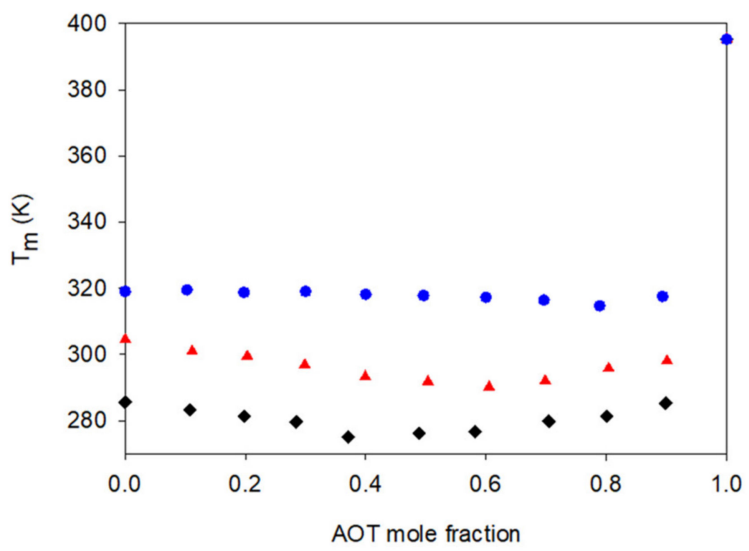

Figure 1. Melting curves of the systems AOT + PEG: • AOT + PEG-2000, $\triangle$ AOT + PEG-1000, $\bullet$ AOT + PEG-600.

The system AOT + PEG-2000 exhibited a minimum melting temperature of $314 \mathrm{~K}$, when the surfactant mole fraction was ca. 0.80 , a value very close to the melting point of the PEG-2000 (319 K). In fact, all the melting points found for this system were similar to the melting point of the polymer, even for mixtures with a high proportion of surfactant. The 
system AOT + PEG-1000 exhibited a minimum of $290 \mathrm{~K}$ (14 K lower than that corresponding to the polymer) for a mixture with AOT mole fraction of ca. 0.60 . Depending on the ambient conditions, this mixture could be in a solid or liquid state. For the system AOT + PEG-600, a minimum melting point of $275 \mathrm{~K}$ was found for a mixture with surfactant mole fraction of ca. 0.40 . This temperature represents a significant decrease $(129 \mathrm{~K})$ from the melting point of the pure surfactant, and a slight decrease $(10 \mathrm{~K})$ compared to the pure polymer. Consequently, this mixture of AOT and PEG-600 was considered as an interesting eutectic for EOR applications.

\subsection{Thermal Stability}

Regular onset decomposition temperature $T_{d}$ and $5 \%$ onset decomposition temperature $T_{d, 5 \%}$ for the pure components are presented in Table 2. TGA thermograms are included in the Supplementary Materials. Again, differences regarding values previously published were likely due to impurities, especially water, in the samples. In addition, the eutectic mixture was subjected to thermogravimetric analysis in order to determine its decomposition temperature. Figure 2 shows the dynamic TGA thermogram of the mixture, as well as that of the pure components.

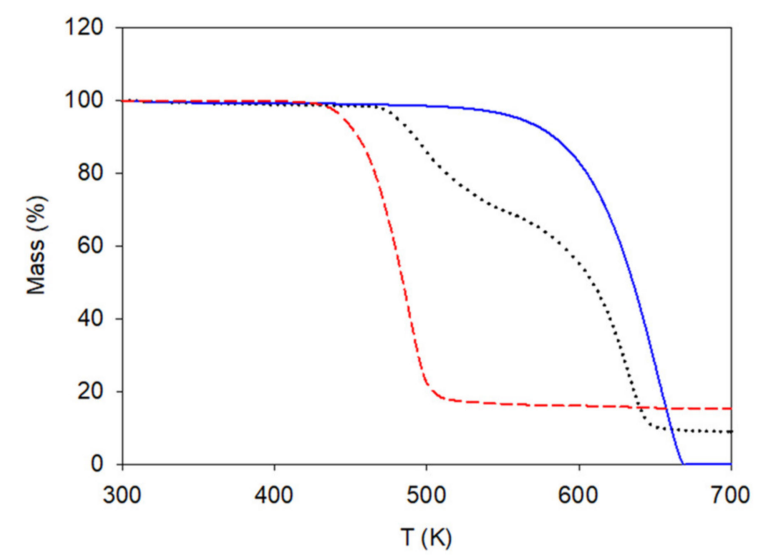

Figure 2. Dynamic TGA thermograms of the eutectic mixture (black, dotted line), AOT (red, dashed line), and PEG-600 (solid, blue line).

The $T_{d, 5 \%}$ value obtained for the eutectic mixture was $473 \mathrm{~K}$, while $T_{d}$ was $575 \mathrm{~K}$. Unlike the pure components, the mixture exhibited a two-step decomposition that could be related to an independent decomposition of surfactant and polymer.

\subsection{Physical Characterization of the Eutectic}

Water content of the AOT + PEG-600 eutectic was 479 ppm. Density and viscosity are among the most relevant properties of fluid systems for process design. Both properties were measured for the eutectic at temperatures from $288.15 \mathrm{~K}$ to $348.15 \mathrm{~K}$, every $10 \mathrm{~K}$, at atmospheric pressure. Experimental data are shown in Figure 3. Numerical data can be seen in Table S2 of the Supplementary Materials.

Equation (10) was obtained as a mathematical model to express the linear relationship between the density and temperature:

$$
\rho=1.3619-7.8551 \times 10^{-4} \times T
$$

where $\rho$ is the density in $\mathrm{g} / \mathrm{cm}^{3}$ and $T$ is the absolute temperature, expressed in $\mathrm{K}$. The standard deviation of the fit was $7 \times 10^{-5} \mathrm{~g} / \mathrm{cm}^{3}$. 


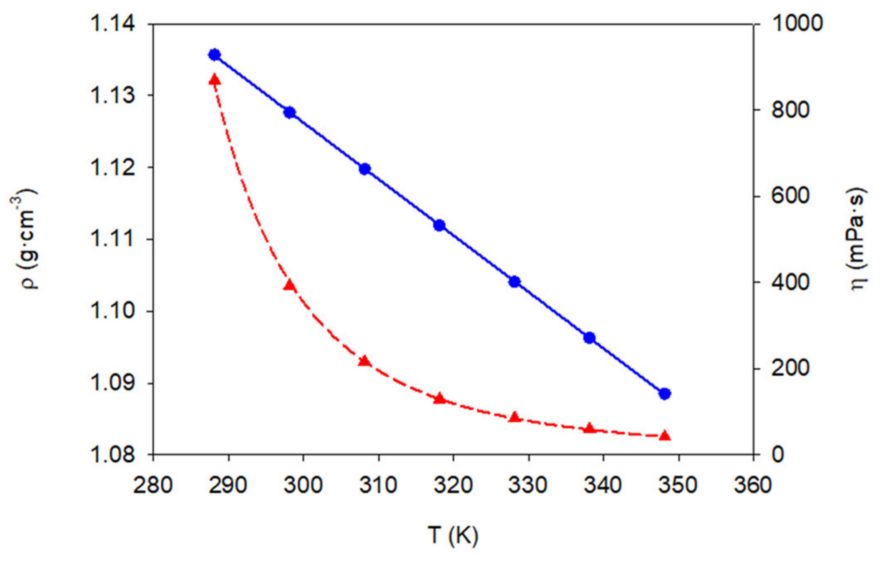

Figure 3. Physical properties of the eutectic mixture of AOT + PEG-600. Legend: • density, $\Delta$ viscosity. The blue, solid line and the red, dashed line represent the correlations by means of Equations (10) and (11), respectively.

The variation of the viscosity $(\eta)$ with temperature was correlated using the VogelFulcher-Tammann (VFT) equation, in particular the modified version by Cohen and Turnbull [40]:

$$
\eta=2.4944 \times 10^{-2} \times T^{0.5} \times \exp \left(\frac{668.17}{T-200.42}\right)
$$

where $\eta$ is the viscosity in $\mathrm{mPa} \cdot \mathrm{s}$ and $T$ is the absolute temperature, expressed in $\mathrm{K}$. The relative standard deviation of the fit was $1.9 \times 10^{-2}$.

Results of the correlations are also shown in Figure 3. As can be seen, the correlation equations describe very well the trends exhibited by the experimental data points.

\subsection{EOR}

\subsubsection{Injectability}

Several formulations with $1 \mathrm{wt} \%$ AOT + PEG-600 eutectic and $\mathrm{NaCl}$ concentrations ranging from 1 to $5 \mathrm{wt} \%$ were prepared and visually analyzed after $24 \mathrm{~h}$. Cloudiness or precipitation problems were found for solutions with $\mathrm{NaCl}$ concentration higher than $2 \mathrm{wt} \%$. For this reason, these formulations were discarded.

The high value obtained for the decomposition temperature of the eutectic (Section 3.2) implies that no problems with this variable are expected regarding injectability or operation.

\subsubsection{Water/Oil IFT Reduction}

Salinity of the aqueous phase has a strong influence on the IFT of crude oil/aqueous systems. For that reason, formulations of $1 \mathrm{wt} \%$ AOT + PEG-600 eutectic and $0 \mathrm{wt} \%$ (pure water), $0.5 \mathrm{wt} \%$, or $1 \mathrm{wt} \% \mathrm{NaCl}$ were prepared, and their dynamic IFT with crude oil was determined. The results are shown in Figure 4. A minimum value of $5.1 \times 10^{-2} \mathrm{mN} / \mathrm{m}$ was obtained for the $0.5 \mathrm{wt} \% \mathrm{NaCl}$ concentration, and, hence, it was selected as the optimum salinity. 


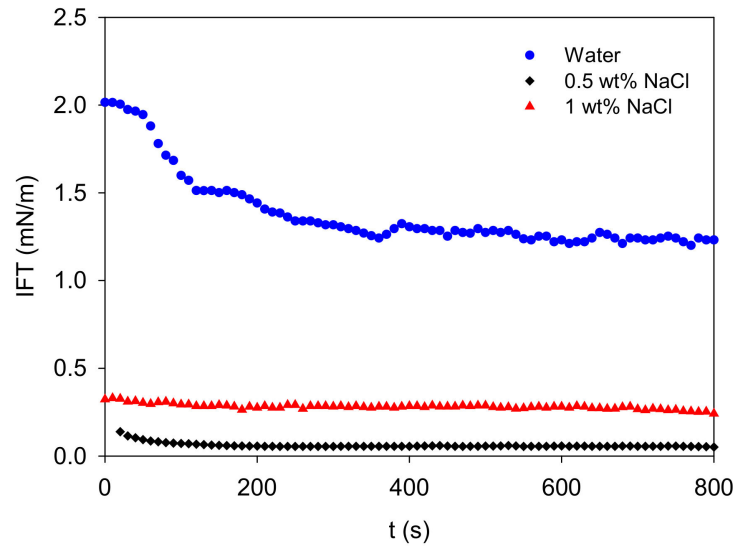

Figure 4. Effect of $\mathrm{NaCl}$ concentration on dynamic IFT between crude oil and formulations with $1 \mathrm{wt} \%$ eutectic mixture (AOT + PEG-600).

The optimized formulation, consisting of an aqueous formulation with $1 \mathrm{wt} \%$ eutectic mixture and $0.5 \mathrm{wt} \% \mathrm{NaCl}$, was stable over time. Its physical properties at $298.15 \mathrm{~K}$ are shown in Table 3.

Table 3. Physical properties of the optimized formulation at $298.15 \mathrm{~K}$.

\begin{tabular}{cc}
\hline Property & Value \\
\hline$\rho\left(\mathrm{g} / \mathrm{cm}^{3}\right)$ & 1.002384 \\
$\eta(\mathrm{mPa} \cdot \mathrm{s})$ & 1.0209 \\
\hline
\end{tabular}

\subsubsection{Adsorption Kinetics}

An adsorption kinetics test was carried out in order to find the time taken to reach equilibrium between the optimized formulation and sandstone rock. The equilibrium time was found to be $10 \mathrm{~h}$, as shown in Figure $5 \mathrm{a}$.

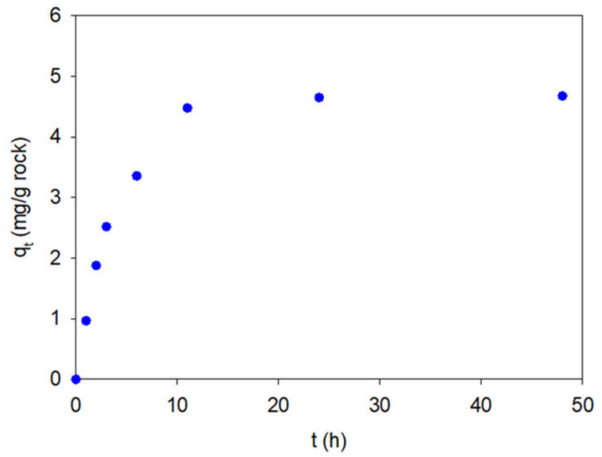

(a)

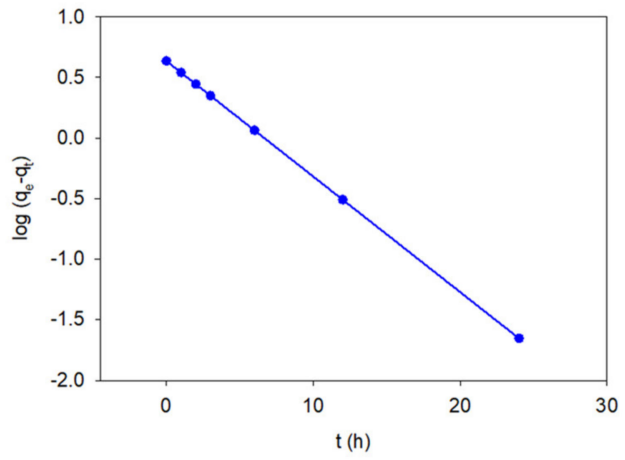

(b)

Figure 5. (a) Evolution of the surfactant adsorption with time. (b) Pseudo-first order fit (Equation (3)).

Pseudo-first- and pseudo-second-order models were applied to describe the adsorption kinetics. It was found that the adsorption of the AOT + PEG-600 eutectic onto sandstone obeyed the pseudo-first-order model, since the standard deviation of the fit was lower, as shown in Table 4. The corresponding linear fit to this model is shown in Figure 5b. 
Table 4. Parameters and standard deviation of kinetics models for adsorption of the optimized formulation on sandstone rock.

\begin{tabular}{lcc}
\hline \multicolumn{1}{c}{ Model } & Parameter & Standard Deviation (mg/g) \\
\hline Pseudo-first order & K1 $(\mathrm{h}-1)=0.220$ & 0.182 \\
Pseudo-second order & $\mathrm{K} 2(\mathrm{~h}-1)=0.337$ & 0.240 \\
\hline
\end{tabular}

\subsubsection{Static Adsorption Experiments}

Adsorption of AOT alone or combined with the polymer, as a function of initial surfactant concentration, is shown in Figure 6. It can be observed that the adsorption density increased with the initial surfactant concentration. This behavior is in agreement with other adsorption studies on sandstone rocks $[24,25,41]$.

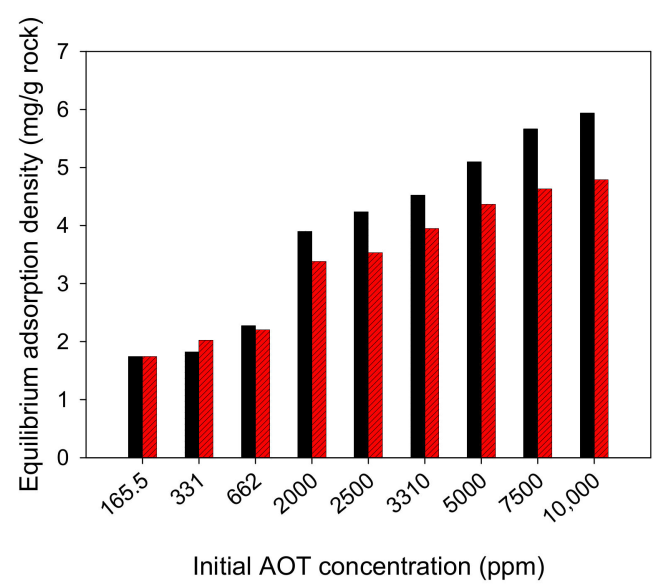

Figure 6. Adsorption of the eutectic mixture (red, shaded columns) and of pure AOT (black columns) in crushed sandstone as a function of the initial surfactant concentration.

Experimental data of adsorption isotherms were fit to Langmuir and Freundlich models. The fit parameters and standard deviations are shown in Table 5.

Table 5. Langmuir and Freundlich isotherms parameters obtained from non-linear fit for AOT and for the AOT + PEG-600 eutectic.

\begin{tabular}{cccc}
\hline Model & Parameter & AOT & Eutectic \\
\hline \multirow{2}{*}{ Langmuir } & $q_{m}(\mathrm{mg} / \mathrm{g})$ & 4.848 & 3.927 \\
& $\begin{array}{c}K_{L}(\mathrm{~L} / \mathrm{mg}) \\
\text { Standard deviation } \\
(\mathrm{mg} / \mathrm{g})\end{array}$ & $4.25 \times 10^{-3}$ & $8.88 \times 10^{-3}$ \\
& $K_{F}(\mathrm{~L} / \mathrm{g})$ & 0.655 & 0.497 \\
\multirow{2}{*}{ Freundlich } & $1 / n$ & 0.429 & 0.693 \\
& Standard deviation & 0.294 & 0.214 \\
& $(\mathrm{mg} / \mathrm{g})$ & 0.186 & 0.153 \\
\hline
\end{tabular}

According to the standard deviations (Table 5), the Freundlich model describes the adsorption equilibrium much better than the Langmuir model. Consequently, multilayer adsorption is assumed for both AOT and the AOT + PEG-600 eutectic. Adsorption data are presented as a function of equilibrium concentrations in Figure 7 to show the fit of the Freundlich model to the experimental data. Interestingly, Figures 6 and 7 show that the amount of adsorbed surfactant was significantly lower when the surfactant was used as a part of the eutectic mixture. This phenomenon has been previously reported in the literature for flooding with combinations of surfactant and polymer [42]. When the polymer flows in front of the surfactant slug, the rocky formation is covered by the polymer and fewer sites are available for the surfactant adsorption to occur (competitive adsorption). 


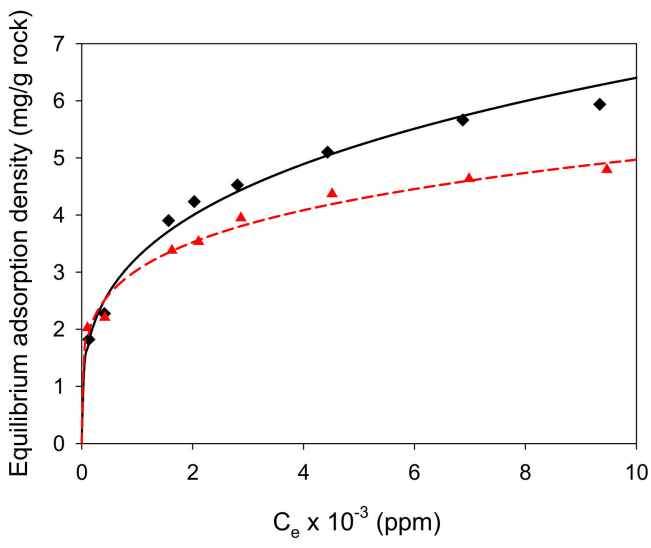

Figure 7. Freundlich isotherm fit for the adsorption of AOT and the AOT + PEG-600 eutectic. Dots represent experimental data for: $\bullet$ AOT and $\Delta$ eutectic. Black, solid line and red, dashed line represent the Freundlich isotherm fit for AOT and the eutectic mixture, respectively.

Adsorption of ionic surfactants is mainly dependent on the nature of the rock surface and the chemical structure of the surfactant. Sandstone rock is composed of quartz and silicate-like minerals, which are negatively charged components. AOT is an anionic, negatively charged surfactant, so repulsion between the rock surface and the surfactant prevents adsorption from occurring [43]. Equilibrium adsorption values ranged from 1.7 to $4.8 \mathrm{mg}$ of surfactant adsorbed per gram of rock (Figure 6), values relatively high but expected, due to the small size of the sandstone particles used in the study. Similar values have been previously reported [44].

\subsubsection{Oil Recovery}

A core flooding run was performed in a fresh sandstone core, and the main results are summarized in Table 6 . The recovery test was started with a secondary water flooding step, injecting $5 \mathrm{PV}$ of brine $(0.5 \mathrm{wt} \% \mathrm{NaCl})$ until no more oil was recovered. Subsequently, $4.41 \mathrm{PV}$ of the optimized formulation were injected during tertiary recovery, until reaching the residual oil saturation $\left(S_{o r}\right)$. An additional oil recovery of $34.18 \%$ of the OOIP was achieved, thus reducing the residual oil saturation down to $8.51 \%$. The results obtained in the core flooding experiment show that the use of the eutectic mixture leads to a significant improvement in oil recovery.

Table 6. Summary of core-flooding test.

\begin{tabular}{lc}
\hline \multicolumn{1}{c}{ Parameter } & Value \\
\hline Pore volume, PV $\left(\mathrm{cm}^{3}\right)$ & 16.20 \\
Porosity of the core $(\%)$ & 18.32 \\
Permeability $(\mathrm{mD})$ & 80.88 \\
OOIP $\left(\mathrm{cm}^{3}\right)$ & 12.73 \\
Initial oil saturation, $S_{o i}(\%)$ & 78.72 \\
Initial water saturation, $S_{w i}(\%)$ & 21.28 \\
Brine injected during secondary recovery $(\mathrm{PV})$ & 4.99 \\
ORWF $(\% O O I P)$ & 55.01 \\
Residual oil saturation after water flooding, & 35.42 \\
$S_{\text {owf }}(\%)$ & \\
Optimized formulation injected during tertiary & 4.41 \\
recovery (PV) & 34.18 \\
AOR $(\% O O I P)$ & 8.51 \\
Residual oil saturation after surfactant flooding & 89.19 \\
$S_{o s f}(\%)$ & \\
Cumulative oil recovery (\%OOIP) & \\
\hline
\end{tabular}


The main oil recovery mechanism was the IFT reduction that led to an increase in the capillary number. The increase of the viscosity did not play a significant role, since the viscosity of the injected fluid was similar to the viscosity of water (Table 3). However, the use of the polymer reduced surfactant adsorption, thus improving the economy of the process.

A comparison of the main results obtained in this investigation and previous experimental studies with eutectics is shown in Table 7. It should be highlighted that previously proposed eutectics did not combine surfactant and polymer, as in this case. Rather, they combined $\mathrm{ChCl}$ with different hydrogen bond donors. None of the previous works $[15,16,18,19]$ achieved ultra-low IFT or a value as low as $0.051 \mathrm{mN} / \mathrm{m}$ reported herein. Additional oil recoveries in these literature precedents ranged from 15.8 to $48.4 \%$ OOIP, with this upper limit being represented by the only value greater than our result herein. However, the authors of that work [19] had to resort to the addition of a traditional surfactant (5 ppm of CTAB) to the eutectic in order to improve the formulation. Static adsorption tests were performed for the eutectic and CTAB separately, but no adsorption study of the optimized formulation was carried out. On the other hand, concentrations previously proposed of $50 \%$ of eutectic (see Table 7 ) are far too high for real applications.

Table 7. Comparison of results obtained in this work and in previous studies.

\begin{tabular}{|c|c|c|c|c|c|c|}
\hline Authors & Eutectic Mixture & Concentration & $\begin{array}{l}\text { Rock } \\
\text { Type }\end{array}$ & $\underset{(\mathrm{mN} / \mathrm{m})}{\mathrm{IFT}}$ & $\begin{array}{l}\text { Adsorption } \\
\text { (mg/g Rock) }\end{array}$ & AOR (\%OOIP) \\
\hline Mohsenzadeh et al. [15] & $\begin{array}{c}\text { ChCl:Glycerol (1:2) } \\
\text { ChCl:Urea (1:2) }\end{array}$ & $50 w t \%$ & $\begin{array}{l}\text { Berea } \\
\text { sandstone }\end{array}$ & $\begin{array}{c}40(298.15 \mathrm{~K}) \\
31.3(301.15 \mathrm{~K})\end{array}$ & - & $\begin{array}{l}29.8(353.15 \mathrm{~K}) \\
30.8(333.15 \mathrm{~K})\end{array}$ \\
\hline Shuwa et al. [16] & $\begin{array}{c}\text { ChCl:Ethylene Glycol } \\
(1: 2)\end{array}$ & $50 \mathrm{vol} \%$ & $\begin{array}{c}\text { Berea } \\
\text { sandstone }\end{array}$ & $12(298.15 \mathrm{~K})$ & - & $15.8(353.15 \mathrm{~K})$ \\
\hline \multirow{4}{*}{ El-hoshoudy et al. [18] } & \multirow{4}{*}{$\begin{array}{c}\text { ChCl:Urea (1:2) } \\
\text { ChCl:Thio urea (1:2) } \\
\text { ChCl:Ethylene Glycol } \\
(1: 2) \\
\text { ChCl: Glycerol (1:2) }\end{array}$} & \multirow{4}{*}{$50 \mathrm{vol} \%$} & \multirow{4}{*}{$\begin{array}{c}\text { Berea } \\
\text { sandstone }\end{array}$} & $4.3(313.15 \mathrm{~K})$ & 9.5 & 25 \\
\hline & & & & $0.57(313.15 \mathrm{~K})$ & Ca. 12 & 29 \\
\hline & & & & $5(313.15 \mathrm{~K})$ & Ca. 8.5 & 15 \\
\hline & & & & $1.52(313.15 \mathrm{~K})$ & Ca. 10.5 & 22 \\
\hline Al-Wahaibi et al. [3] & $\begin{array}{l}\text { ChCl:Malonic acid (1:0.5) } \\
\text { ChCl:Malonic acid }(1: 1)\end{array}$ & $50 \mathrm{vol}^{\%}$ & $\begin{array}{l}\text { Berea } \\
\text { sandstone }\end{array}$ & $\begin{array}{c}21.9(318.15 \mathrm{~K}), \\
9.8(353.15 \mathrm{~K}) \\
21.9(318.15 \mathrm{~K}) \\
8.3(353.15 \mathrm{~K})\end{array}$ & - & $\begin{array}{c}4.1(318.15 \mathrm{~K}), 8.0 \\
(353.15 \mathrm{~K}) \\
6.6(318.15 \mathrm{~K}), 8.2 \\
(353.15 \mathrm{~K})\end{array}$ \\
\hline Sanati et al. [19] & $\begin{array}{l}\text { ChCl:Citric acid (1:1) } \\
\text { and } 5 \text { ppm of CTAB }\end{array}$ & $1 \mathrm{vol} \%$ & $\begin{array}{l}\text { Carbonate } \\
\text { rock }\end{array}$ & 0.5 (ambient) & $\begin{array}{l}\text { Ca. } 1 \text { DES } \\
\text { Ca. } 10 \text { CTAB }\end{array}$ & 48.4 \\
\hline Present study & AOT:PEG-600 (1.5:1) & $1 \mathrm{wt} \%$ & $\begin{array}{c}\text { Berea } \\
\text { Sandstone }\end{array}$ & $0.051(298.15 \mathrm{~K})$ & 4.75 & 34.18 (ambient) \\
\hline
\end{tabular}

\section{Conclusions}

Surfactants and polymers are promising EOR chemicals that are currently being combined in order to achieve the water/oil IFT reduction required to enhance the mobility of the oil retained in the pores of the rocks, while also avoiding adverse mobility ratios. The usual solid character of these chemicals at room conditions may hamper the preparation of the corresponding formulations. The main conclusion of this study is that polymers and surfactants can be adequately selected to form eutectics, thus facilitating the preparation of EOR formulations due to the liquid character of the mixture.

This has been shown through the combination of AOT with PEG. The mixtures showed melting temperatures significantly lower than those corresponding to the surfactant and slightly lower than those corresponding to the polymers. The lower the molecular weight of the polymer, the greater the reduction in the melting point compared to that of the pure surfactant. The most promising combination was found for AOT with PEG-600 at a 40:60 molar ratio. Such combination formed a eutectic mixture with a melting point of $275 \mathrm{~K}$, thermally stable up to $473 \mathrm{~K}\left(T_{d, 5 \%}\right)$.

Based on the reduction of the IFT, an aqueous optimal formulation containing $1 \mathrm{wt} \%$ of the AOT + PEG-600 eutectic and $0.5 \mathrm{wt} \% \mathrm{NaCl}$ was designed for EOR. The formulation was capable of reducing water/oil IFT to a value of $5.1 \times 10^{-2} \mathrm{mN} / \mathrm{m}$. Moreover, the combination of the polymer with the surfactant reduced the adsorption of the latter on 
the rocks. According to the AOR achieved (34.18\% of OOIP), it can be concluded that the formulation is promising for sandstone rocks and for reservoirs with low salinity conditions. Future outcomes are expected on eutectics stable in harsh environmental conditions, a challenge for any EOR method.

Supplementary Materials: The following are available online at https://www.mdpi.com/article/10 .3390 /app11178164/s1. Figures S1-S4: ${ }^{1}$ H NMR spectra. Figures S5-S12: TGA and DSC thermograms. Table S1: Melting temperatures for AOT + PEG mixtures. Table S2: Physical properties for the AOT + PEG-600 eutectic.

Author Contributions: C.G.: experimental, analysis, original draft preparation. A.S. (Alba Somoza): EOR experimental supervision, analysis, original draft preparation. H.R.: thermal studies' supervision, analysis, editing. A.S. (Ana Soto): conceptualization, supervision, writing, funding acquisition. All authors have read and agreed to the published version of the manuscript.

Funding: This research was funded by the Ministry of Science and Innovation and State Research Agency of Spain throughout project PGC2018-097342-B-I00, co-funded by the European Regional Development Fund.

Institutional Review Board Statement: Not applicable.

Informed Consent Statement: Not applicable.

Acknowledgments: A. Somoza acknowledges predoctoral financial support (grant ref. PRE2019089101). The authors thank Repsol (A Coruña) for providing the crude oil used for the experiments.

Conflicts of Interest: The authors declare no conflict of interest.

\section{References}

1. Capuano, L. International energy outlook 2020 (IEO2020). US Energy Inf. Adm. 2020, 2020, 1-7.

2. Saxena, N.; Goswami, A.; Dhodapkar, P.K.; Nihalani, M.C.; Mandal, A. Bio-based surfactant for enhanced oil recovery: Interfacial properties, emulsification and rock-fluid interactions. J. Pet. Sci. Eng. 2019, 176, 299-311. [CrossRef]

3. Al-Wahaibi, I.; Al-Wahaibi, Y.; Al-Hajri, R.; Jibril, B.; Shuwa, S. The novel use of malonic acid-based deep eutectic solvents for enhancing heavy oil recovery. Int. J. Oil Gas Coal Technol. 2019, 20, 31-54. [CrossRef]

4. Vishnyakov, V.; Suleimanov, B.; Salmanov, A.; Zeynalov, E. Primer on Enhanced Oil Recovery; Gulf Professional Publishing: Cambridge, MA, USA, 2019; ISBN 9780128176320.

5. Franchi, J.R. Principles of Applied Reservoir Simulation; Gulf Professional Publishing: Cambridge, MA, USA, 2018; ISBN 9780128155639.

6. Horgue, P.; Soulaine, C.; Franc, J.; Guibert, R.; Debenest, G. An open-source toolbox for multiphase flow in porous media. Comput. Phys. Commun. 2015, 187, 217-226. [CrossRef]

7. Muggeridge, A.; Cockin, A.; Webb, K.; Frampton, H.; Collins, I.; Moulds, T.; Salino, P. Recovery rates, enhanced oil recovery and technological limits. Philos. Trans. R. Soc. A Math. Phys. Eng. Sci. 2014, 372, 20120320. [CrossRef]

8. Druetta, P.; Picchioni, F. Surfactant flooding: The influence of the physical properties on the recovery efficiency. Petroleum 2020, 6 , 149-162. [CrossRef]

9. Negin, C.; Ali, S.; Xie, Q. Most common surfactants employed in chemical enhanced oil recovery. Petroleum 2017, 3, 197-211. [CrossRef]

10. Atta, D.Y.; Negash, B.M.; Yekeen, N.; Habte, A.D. A state-of-the-art review on the application of natural surfactants in enhanced oil recovery. J. Mol. Liq. 2021, 321, 114888. [CrossRef]

11. Gbadamosi, A.O.; Junin, R.; Manan, M.A.; Agi, A.; Yusuff, A.S. An Overview of Chemical Enhanced Oil Recovery: Recent Advances and Prospects. Springer: Berlin/Heidelberg, Germany, 2019; Vol. 9, ISBN 0123456789.

12. Sheng, J.J. Modern Chemical Enhanced Oil Recovery; Elsevier: Amsterdam, The Netherlands, 2011; ISBN 9781856177450.

13. Sheng, J.J. Enhanced Oil Recovery. Field Case Studies; Elsevier: Amsterdam, The Netherlands, 2013; ISBN 9780123865458.

14. Martins, M.A.R.; Pinho, S.P.; Coutinho, J.A.P. Insights into the nature of eutectic and deep eutectic mixtures. J. Sol. Chem. 2019, 48, 962-982. [CrossRef]

15. Mohsenzadeh, A.; Al-Wahaibi, Y.; Jibril, A.; Al-Hajri, R.; Shuwa, S. The novel use of deep eutectic solvents for enhancing heavy oil recovery. J. Pet. Sci. Eng. 2015, 130, 6-15. [CrossRef]

16. Shuwa, S.M.; Jibril, B.Y.; Al-Wahaibi, Y.M.; Al-Hajri, R.S. Heavy-oil-recovery enhancement with choline chloride/ethylene glycol-based deep eutectic solvent. SPE J. 2015, 20, 79-87. [CrossRef]

17. Lee, J.; Babadagli, T. Comprehensive methodology for chemicals and nano materials screening for heavy oil recovery using microemulsion characterization. J. Pet. Sci. Eng. 2018, 171, 1099-1112. [CrossRef] 
18. El-hoshoudy, A.N.; Soliman, F.S.; Mansour, E.M.; Zaki, T.; Desouky, S.M. Experimental and theoretical investigation of quaternary ammonium-based deep eutectic solvent for secondary water flooding. J. Mol. Liq. 2019, 294, 111621. [CrossRef]

19. Sanati, A.; Rahmani, S.; Nikoo, A.H.; Malayeri, M.R.; Busse, O.; Weigand, J.J. Comparative study of an acidic deep eutectic solvent and an ionic liquid as chemical agents for enhanced oil recovery. J. Mol. Liq. 2021, 329, 115527. [CrossRef]

20. Sanati, A.; Malayeri, M.R. CTAB adsorption onto dolomite in the presence of ionic liquid and deep eutectic solvent: Experimental and theoretical studies. J. Mol. Liq. 2021, 325, 115176. [CrossRef]

21. Gabbott, P. (Ed.) Principles and Applications of Thermal Analysis; Blackwell Publishing: New Delhi, India, 2008 ; ISBN 9781405131711.

22. Rodríguez-Palmeiro, I.; Rodríguez-Escontrela, I.; Rodríguez, O.; Soto, A.; Reichmann, S.; Amro, M.M. Tributyl(tetradecyl)phosphonium chloride ionic liquid for surfactant-enhanced oil recovery. Energy Fuels 2017, 31, 6758-6765. [CrossRef]

23. Vonnegut, B. Rotating bubble method for the determination of surface and interfacial tensions. Rev. Sci. Instrum. 1942, 13, 6 . [CrossRef]

24. Hanamertani, A.S.; Pilus, R.M.; Idris, A.K.; Irawan, S.; Tan, I.M. Ionic liquids as a potential additive for reducing surfactant adsorption onto crushed Berea sandstone. J. Pet. Sci. Eng. 2018, 162, 480-490. [CrossRef]

25. Ahmadi, M.A.; Shadizadeh, S.R. Spotlight on the new natural surfactant flooding in carbonate rock samples in low salinity condition. Sci. Rep. 2018, 8, 1-15. [CrossRef]

26. Liu, Z.; Zhao, G.; Brewer, M.; Lv, Q.; Sudhölter, E.J.R. Comprehensive review on surfactant adsorption on mineral surfaces in chemical enhanced oil recovery. Adv. Colloid Interfac. Sci. 2021, 294, 102467. [CrossRef]

27. Bin Dahbag, M.; AlQuraishi, A.; Benzagouta, M. Efficiency of ionic liquids for chemical enhanced oil recovery. J. Petrol. Explor. Prod. Technol. 2015, 5, 353-361. [CrossRef]

28. Nandwani, S.K.; Malek, N.I.; Chakraborty, M.; Gupta, S. Potential of a novel surfactant slug in recovering additional oil from highly saline calcite cores during the EOR Process: Synergistic blend of surface active ionic liquid and nonionic surfactant. Energy Fuels 2019, 33, 541-550. [CrossRef]

29. Wheaton, R. Fundamentals of Applied Reservoir Engineering: Appraisal, Economics and Optimization; Elsevier: Amsterdam, The Netherlands, 2016; ISBN 9780081010198.

30. Haddad, H.; Al Kobaisi, M. Influence of moisture content on the thermal and mechanical properties and curing behavior of polymeric matrix and polymer concrete composite. Mater. Des. 2013, 49, 850-856. [CrossRef]

31. Seddon, K.R.; Stark, A.; Torres, M.J. Influence of chloride, water, and organic solvents on the physical properties of ionic liquids. Pure Appl. Chem. 2000, 72, 2275-2287. [CrossRef]

32. Yonekura, R.; Grinstaff, M.W. The effects of counterion composition on the rheological and conductive properties of mono- and diphosphonium ionic liquids. Phys. Chem. Chem. Phys. 2014, 16, 20608-20617. [CrossRef]

33. Brown, P.; Butts, C.P.; Eastoe, J.; Grillo, I.; James, C.; Khan, A. New catanionic surfactants with ionic liquid properties. J. Colloid Interfac. Sci. 2013, 395, 185-189. [CrossRef]

34. Pramono, E.; Utomo, S.B.; Wulandari, V.; Zahrotul, A.W.; Clegg, F. The effect of polyethylene glycol Mw 400 and 600 on stability of Shellac Waxfree. J. Phys. Conf. Ser. 2016, 776, 012054. [CrossRef]

35. Sari, A. Composites of polyethylene glycol (PEG600) with gypsum and natural clay as new kinds of building PCMs for low temperature-thermal energy storage. Energy Build. 2014, 69, 184-192. [CrossRef]

36. Kou, Y.; Wang, S.; Luo, J.; Sun, K.; Zhang, J.; Tan, Z.; Shi, Q. Thermal analysis and heat capacity study of polyethylene glycol (PEG) phase change materials for thermal energy storage applications. J. Chem. Thermodyn. 2019, 128, 259-274. [CrossRef]

37. Thanakkasaranee, S.; Kim, D.; Seo, J. Preparation and characterization of poly(ether-block-amide)/polyethylene glycol composite films with temperature- dependent permeation. Polymers 2018, 10, 225. [CrossRef] [PubMed]

38. Kuru, A.; Aksoy, S.A. Cellulose-PEG grafts from cotton waste in thermo-regulating textiles. Text. Res. J. 2014, 84, 337-346. [CrossRef]

39. Jia, M.; Sha, A.; Jiang, W.; Wang, W.; Li, J.; Dai, J.; Lu, Z. Laboratory evaluation of poly(ethylene glycol) for cooling of asphalt pavements. Constr. Build. Mater. 2021, 273, 121774. [CrossRef]

40. Cohen, M.H.; Turnbull, D. Molecular transport in liquids and glasses. J. Chem. Phys. 1959, 31, 1164-1169. [CrossRef]

41. Lv, W.; Bazin, B.; Ma, D.; Liu, Q.; Han, D.; Wu, K. Static and dynamic adsorption of anionic and amphoteric surfactants with and without the presence of alkali. J. Pet. Sci. Eng. 2011, 77, 209-218. [CrossRef]

42. Druetta, P.; Picchioni, F. Surfactant-polymer flooding: Influence of the injection scheme. Energy Fuels 2018, 32, 12231-12246. [CrossRef]

43. Bera, A.; Kumar, T.; Ojha, K.; Mandal, A. Adsorption of surfactants on sand surface in enhanced oil recovery: Isotherms, kinetics and thermodynamic studies. Appl. Surf. Sci. 2013, 284, 87-99. [CrossRef]

44. Puerto, M.; Lopez-Salinas, J.; Jian, G.; Hirasaki, G.; Miller, C. Laboratory Studies of Ternary Surfactant Formulation for EOR in Oil-Wet, High-Temperature Carbonate Formations. In Proceedings of the SPE Improved Oil Recovery Conference, Tulsa, OK, USA, 14-18 April 2018. [CrossRef] 